\title{
Construction of Overexpression Vector of ACBP Gene in Zygosaccharomyces rouxii
}

\author{
Fei Chen, Jizhong Han, Lanlan Liu, Jianwen Hu, Xian Zhang, Bin Zeng* \\ School of Life Science, Jiangxi Science \& Technology Normal University, Nanchang, China \\ Email: 1752144656@qq.com, *Zengtx001@aliyun.com
}

How to cite this paper: Chen, F., Han, J.Z., Liu, L.L., Hu, J.W., Zhang, X. and Zeng, B. (2016) Construction of Overexpression Vector of ACBP Gene in Zygosaccharomyces rouxii. Journal of Biosciences and Medicines, 4, 23-30.

http://dx.doi.org/10.4236/jbm.2016.412004

Received: October 13, 2016

Accepted: November 24, 2016

Published: December 1, 2016

\begin{abstract}
The Zygosaccharomyces rouxii is a kind of fermentation yeast which yield flavoring substance in the production of soy sauce. In order to the overexpression of the target protein in wild type strains, we choose $\mathrm{PYEs}_{2.0}$ as the original carrier, the acyl-coA binding protein (ACBP) and GFP gene have been cloned in the multiple cloning site. The screening of labeled URA3 gene was replaced by KanMX gene which anti G418. The vector was obtained through the screening of G418 at the concentration of 25 ug/ml.
\end{abstract}

\section{Keywords}

Zygosaccharomyces rouxii, Overexpression Vector, Acyl-coA Binding Protein, $\mathrm{PYEs}_{2.0}$

\section{Introduction}

In general, Zygosaccharomyces rouxii often used as a salt tolerant yeast which produced the aroma substances in the late stage of soy sauce [1]. acyl-coA binding protein(ACBP)is an important intermediate in the metabolism of esters. ACBP is unable to bind free fatty acids, but have high affinity for 8 or more carbon atoms of long chain acyl acyl-coA ester [2]. ACBP is combined with acyl coenzyme A ester to play a role in the metabolism of acyl-coA. It can mediate membrane transport of acyl-coA, translocate to mitochondria and microbodies, were involved in the beta oxidation or glycerol biosynthesis. It also can protect the long chain acyl-coA ester is not hydrolyzed by acyl coenzyme A [3] [4] [5].

In the present study, we put the screening marker URA3 gene which is expressed in the auxotrophic strains change for the kanMX gene. This kanMX module was made the known kan' open reading-frame of the E. coli transposon Tn903 fused to transcriptional and translational control sequences of the TEF gene of the filamentous fungus Ash- 
bya gossypii. This hybrid module permits efficient selection of transformants resistantagainst geneticin (G418) [6]. Constructing of such an express vector can be transformed exogenous gene and using G418 to positive screening in wild type strains. In order to study the metabolic mechanism in Wild type strain of Zygosaccharomyces rouxii, we structured the vector which overexpression of ACBP. At first, the Zygosacch aromyces rouxii was screened by G418. After inoculation (the original concentration about $5 \times 10^{6}$ concentration) 48 hours, we founded that $z$. rouxii does not appear monoclonal colony at $25 \mathrm{ug} / \mathrm{mL}$ G418 selective medium. In view of the above, we replaced the URA gene of $\mathrm{pYES}_{2.0}$ of Saccharomyces cerevisiae expression vector with kanMX gene to obtain the G418 resistance. The ACBP and GFP genes were cloned into the multiple cloning sites of the vector, and then transforming and cloning of Zygosaccharomyces rouxii were carried out. Thus, the overexpression vector of ACBP gene had been constructed.

\section{Materials and Methods}

\subsection{Strains and Plasmids}

Escherichia coli DH5a, Zygosaccharomyces rouxii, pEGFP-N1 our laboratory preservation, pPYES $_{2.0}$ was purchased from (You Bia; Youbaobiology), Saccharomyces cerevisiae purchased from CTCC, PFA6a-GFPS65T-kanMX6 purchased from (Hangzhou Bao Sai bio).

\subsection{Main Reagent}

Premix $\mathrm{Taq}^{\text {Ta }}$ (Ex $\mathrm{Taq}^{\text {TM }}$ Version $_{2.0}$ Hot Start forgenomic confirmation PCR), DNA Marker, $\mathrm{pMD}^{\mathrm{m}} 19-\mathrm{T}$ Vector Cloning Kit, All required restriction enzymes were purchased from the TaKaRa (Dalian); Agarose gel DNA Recovery Kit, plasmid small mention kit were purchased from the Tiangen (Beijing); Agarose, ISalcohol are purchased from Sang Biotech (Shanghai). Genome Extraction Kit purchased from the Phygene life sciences.

\subsection{Design and Synthesis of Primers}

According to the nucleotide sequence of pFA6a-GFPS65T-kanMX6, the primers were designed to amplify the KanMX gene sequence, and the NheI and NdeI restriction sites were introduced. According to the NCBI query to the Zygosaccharomyces rouxii ACBP sequence, design primers ACBP-F, ACBP-R and introduced into NotI and XhoI sites and then cloned the GFP in the back of ACBP, in which was introduced into XhoI and XbaI sites. Specific primer base sequence is as Table 1.

\subsection{Prep}

AAll of the primers were synthesized by the Beijing Genomics Institute (BGI).

\subsection{ACBP Cloned}

The amount of slant preservation were respectively Zygosaccharomyces rouxiion YPD 
Table 1. Primer sequences.

\begin{tabular}{cc}
\hline Primer name & Nucleotide sequence \\
KanMX-F & 5'CCATATGGACATGGAGGCCCAGAAT3' \\
KanMX-R & 5'CTAGCTAGCCAGTATAGCGACCAGCA3' \\
ACBP-F & 5'CCGCTCGAGATGGTATCACAATTAT3' \\
ACBP-R & 5'GCTCTAGACTATTGAGAGTACTTCTGCTGT3' \\
GFP-F & 5'CCGCTCGAGATGGTGAGCAAG3' \\
GFP-R & 5'CTAGTCTAGACTACTTGTACAGCTCGTCCAT3' \\
pYES2-T7-F & 5'TAATACGACTCACTATAGGG3' \\
pYES2-CYC1-R & 5'GTGACATAACTAATTACATGATG3' \\
RV-M & 5'GAGCGGATAACAATTTCACACAGG3' \\
M13-47 & 5'CGCCAGGGTTTTCCCAGTCACGAC3'
\end{tabular}

solid medium $30^{\circ} \mathrm{C}$ culture. And then selected single colony transfer to liquid YPD medium, $30^{\circ} \mathrm{C}, 180 \mathrm{rpm} / \mathrm{min}$ oscillation culture overnight. Take the right amount of bacteria liquid according to the yeast genome Extraction Kit specification for genome extraction.

ACBP PCR system: Zygosaccharomyces rouxii genome as template $2 \mu \mathrm{L}$, ACBP-F, ACBP-R each $1 \mu \mathrm{L}$, Premix Taq (TaKaRa) $25 \mu \mathrm{L}$, added the deionized water up to $50 \mathrm{~L}$.

Reaction conditions: Pre-denaturation at $95^{\circ} \mathrm{C}$ for $5 \mathrm{~min}$; $95^{\circ} \mathrm{C}$ degeneration for 30 seconds, $53^{\circ} \mathrm{C}$ annealing for 30 seconds, $72^{\circ} \mathrm{C}$ Extension for 60 seconds, which were cycled for 30 times, and then $72^{\circ} \mathrm{C}$ extending again for $10 \mathrm{~min}$, set up the final temperature at $12^{\circ} \mathrm{C}$ makeing the hot cover of PCR Amplifier down to room temperature.

\subsection{GFP, KanMX Cloned}

GFP PCR system: used the plasmid of pEGFP-N1 as template $1 \mu \mathrm{L}$, GFP-F, GFP-R each $1 \mu \mathrm{L}$, Premix Taq (TaKaRa) $25 \mu \mathrm{L}$, added the deionized water up to $50 \mu \mathrm{L}$. But the $60^{\circ} \mathrm{C}$ annealing for 30 seconds.

KanMX PCR system: used the plasmid of pFA6a-GFPS65T-kanMX6 as template 1 $\mu \mathrm{L}$, KanMX-F, KanMX-R each $1 \mu \mathrm{L}$, Premix Taq (TaKaRa) $25 \mu \mathrm{L}$, added the deionized water up to $50 \mu \mathrm{L}$. But the $63^{\circ} \mathrm{C}$ annealing for 30 seconds.

\section{Construction of Expression Vector}

Sequencing to verified the amplified sequence and the restriction sites were introduced into the correct, and start construct vector.

\subsection{The G418 Resistance Gene Cloned}

The $\mathrm{T}$ vector with the kanMX gene and the $\mathrm{PYES}_{2.0}$ plasmid had used the NdeI and NheI restriction endonuclease respectively.

Enzymatic syste $(30 \mu \mathrm{L})$ : plasmid $<1 \mathrm{ug}, 10^{\star}$ Buffer $3 \mathrm{~L}$, restriction. 
Endonuclease $1 \mu \mathrm{L}$, up to dd $\mathrm{H}_{2} \mathrm{O} 30 \mu \mathrm{L} .37^{\circ} \mathrm{C}$ water bath $1 \mathrm{~h}$, and then carry on agarose gel electrophoresis, Gel Extraction.

Ligation system $(20 \mu \mathrm{L})$ : To connect the recovered to a fragment containing the same restriction sites, In order to obtained the plasmid PYES-kanMX with G418 resistance screening marker. kanMX fragment: $12 \mu \mathrm{L}$, carrier fragment: $5 \mu \mathrm{L}$, T4DNA ligase $1 \mu \mathrm{L}$, $10^{\star}$ Buffer 2 ul. $16^{\circ} \mathrm{C}$ overnight ligation. The next transformation into competent $\mathrm{DH} 5 \alpha$ cells and then verify positive clone.

\subsection{Cloning the Target Gene of ACBP}

The T vector with the ACBP gene and the PYES-kanMX had used the NotI and XhoI endonuclease respectively and obtained the plasmid PYES-kanMX-ACBP.

The enzymatic system and ligation system had the same way with 3.1 .

\subsection{Cloning the GFP Gene}

This gene connected to the back of the ACBP gene in the multiple cloning site of $\mathrm{PYES}_{2.0}$ plasmid. Used the XhoI and XbaI endonuclease to restriction digesed the $\mathrm{T}$ vector containing GFP fragment and the expression vector PYES-kanMX-ACBP respectively and obtained the plasmid PYES-kanMX-ACBP-GFP.

The enzymatic system and ligation system had the same way with 3.1 .

\section{Results}

\subsection{Cloning of Gene Fragment and DNA Sequencing Comparison}

After recovery and purification, connected the carrier of pMD19-T respectively, and sent to The Beijing Genomics Institute (BGI) to sequencing verification.

According to the above 2.4 and 2.5 experimental method, Agarose gel electrophoresis results were in agreement with the expected results (Figure 1). Gel recovery and purification of amplified products, and then connection to the PMD-19T Cloning vector, Plasmid transfor-mated state feelings E. coli. Bacterial fluid PCR detection also obtained the expected size of the fragment, extraction plasmid to sequencing.

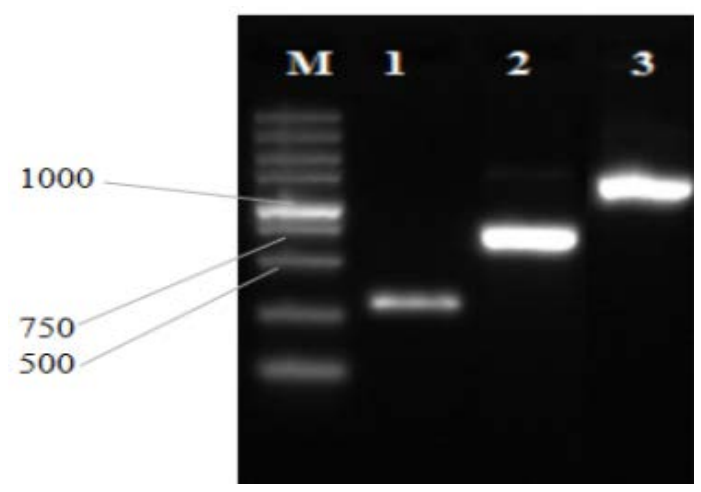

Figure 1. This figure show the amplified target fragment through PCR, Fromleft to right in the order: Marker5000, ACBP, GFP, KanMX. 
The positive clone sequencing was consistent with the sequence Of Genbank, accession numbers: ACBP: NC_012990.1; GFP: Protien.

ID: AII16632.1; kanMX: The sequencing results were consistent with the sequence alignment of kanMX sequences in the pFA6a-GFPS65T-kanMX6 plasmid. Amplificated gene fragments and used T4DNA ligase cloning with the PMD-19T vector, and then transformed E. coli strain. Figure 2 is the Positive clone detection with the gene of ACBP. Figure 3 is the Positive clone detection with the gene of GFP. Figure 4 is the Positive clone detection with the gene of KanMX.

\subsection{Construction of Expression Vector}

Making the $\mathrm{PYES}_{2.0}$ expression vector and PMD-19T containing genes to enzyme digestion, which make it contains the same restriction enzyme site. And then let the gene fragment was connected with expression vector, recombination plasmid transformated state feelings E. coli. Bacterial fluid PCR to detected the positive clone (Figures 5-7). The enzymatic system and ligation system as described in 3.1, 3.2, 3.3. Picked two or more than positive clones expand the culture to plasmid extraction and enzyme digestion to further validation (Figure 8).

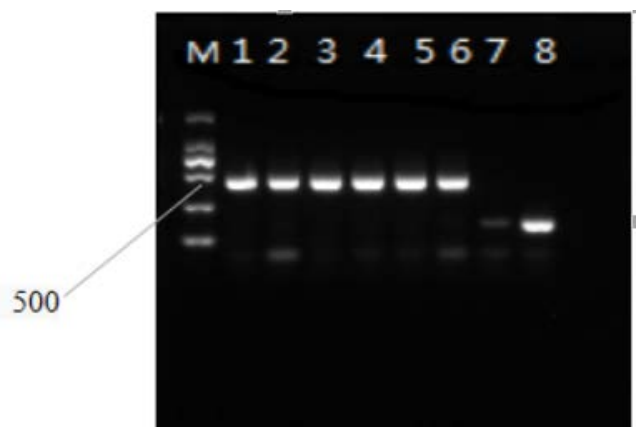

Figure 2. Amplification for ACBP gene in transformed E. coli strain; M.DL 2000 marker; 1, 2, 3, 4, 5, 6 was the PCR production of ACBP gene; 7, 8 was the corresponding colonies are false positive.

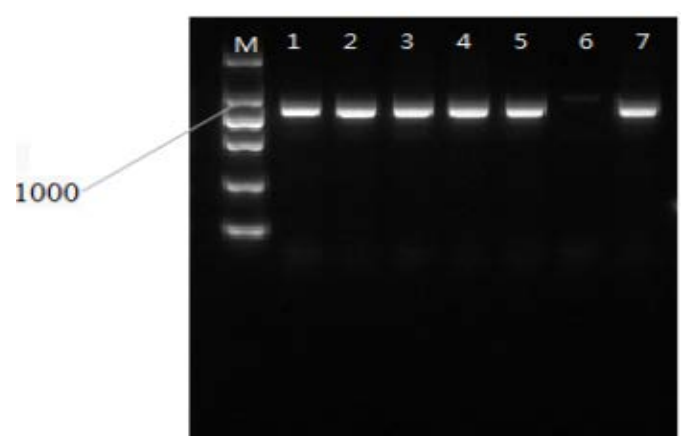

Figure 3. Amplification for GFP gene in transformed E. coli strain; M.DL2000 marker; 1, 2, 3, 4, 5, 7 was the PCR production of GFP gene; 6 was the corresponding colonies are false positive. 


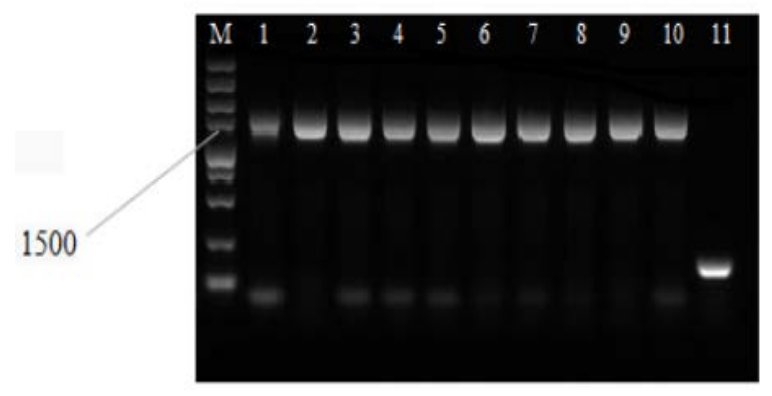

Figure 4. Amplification for KanMX gene in transformed $E$. coli strain; M.DL5000 marker; 1, 2, 3, 4, 5, 6, 7, 8, 9, 10 was the PCR production of KanMX gene; 11 was the corresponding colonies are false positive.

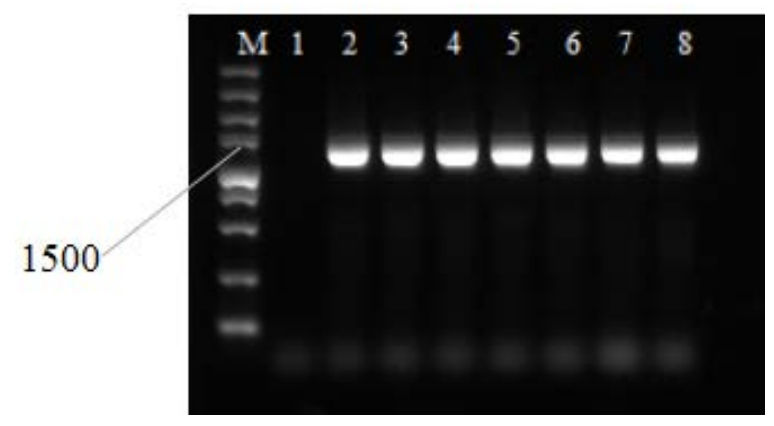

Figure 5. Connected the KanMX gene to PYES2.0 vector and then transformed in E. coli strain; M.DL5000 marker; 2, 3, 4, 5, 6, 7, 8 was the KanMX gene has been linked to the vector; 1 was the corresponding colonies are false positive. Obtained the plasmid named PYES-KanMX.

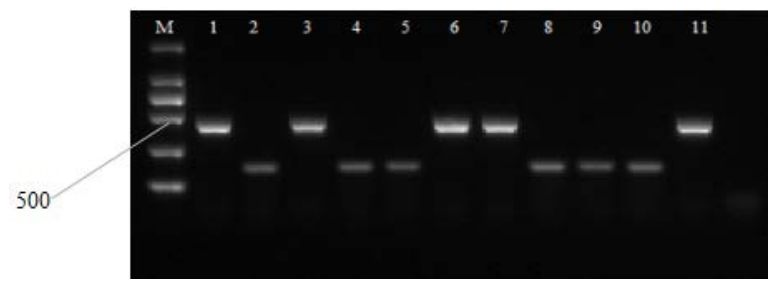

Figure 6. Connected the ACBP gene to PYES-KanMX vector and then transformed in E. coli strain; M.DL2000 marker; 1, 3, 6, 7, 11 was the ACBP gene has been linked to the vector; $2,4,5,8,9,10$ was the corresponding colonies are false positive. Obtained the plasmid named PYESKanMX-ACBP.

\section{Discussion}

ACBP is an 86 - 92 residue protein with a highly conserved sequence found in a wide range of species [7]. Bovine ACBP, rat 1-ACBP, yeast ACBP, and ACBP from Arabidopsis thaliana bind saturated and unsaturated C14-C22-acyl-CoA esters with high specificity and affinity [2], Most of the aroma components in soy sauce are fatty acids 


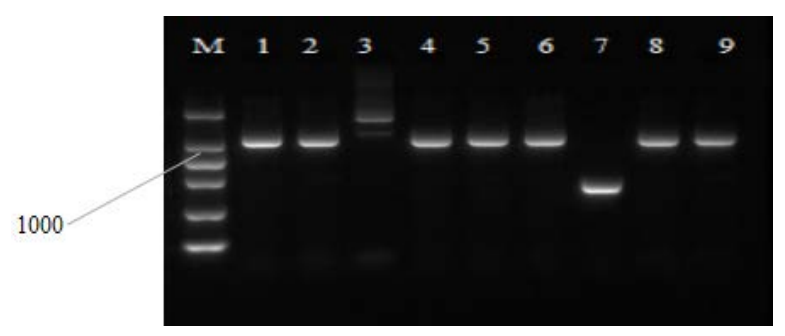

Figure 7. Connected the GFP gene to PYES-KanMX-ACBP vector and then transformed in E. coli strain; M.DL5000 marker 1, 2, 4, 5, 6, 8, 9 was the GFP gene has been linked to the vector; 3,7 was the corresponding colonies are false positive. Obtained the plasmid named PYES-KanMXACBP-GFP.

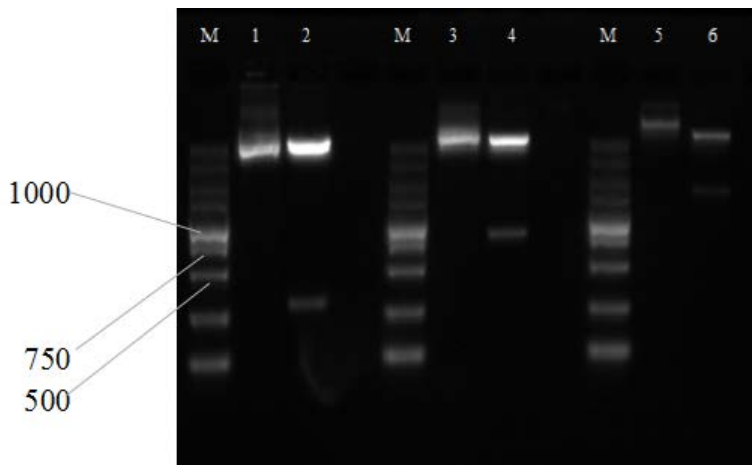

Figure 8. This figure from left to right in order:M.DL5000 marker; 1was the plasmid PYES-KanMX-ACBP and 2 was the Agarose gel electrophoresis after enzyme digestion; 3 was the plasmid PYES-KanMX-ACBP-GFP and 4 was the Agarose gel electrophoresis after enzyme digestion; 5 was the plasmid PYES-KanMX and 6 was the Agarose gel electrophoresis after enzyme digestion.

[8] [9]. It is obvious that have a great relationship between the both. It is necessary to study the ACBP of Zygosaccharomyces rouxii overexpression for the effect of the soy sauce aroma. The construction of overexpression vector wiht GFP gene, in order to we can real-time observation of the ACBP gene of Zygosaccharomyces rouxii. In the next study, we can detect the change of the flavor of the soy sauce in the overexpression vector. This from the point of the molecular to study flavor of soy sauce, the source of the material, and the mechanism, which to improve the process of soy sauce has a great guiding role for us.

\section{Acknowledgements}

This work was supported by these projects in China (31171731, 31460447, 20142BDH80003, 2013-CXTD002, "555 talent project” of Jiangxi Province, Jiangxi Province Key Laboratory of Bioprocess Engineering and Co-Innovation Center for In Vitro Diagnostic Reagents and Devices of Jiangxi Province). 


\section{References}

[1] Golden, D.A., Beuchat, L.R. and Hitchcock, H.L. (1994) Changes in Fatty Acid Composition of Various Lipid Components of Zygosaccharomyces rouxii as Influenced by Solutes, Potassium Sorbate and Incubation Temperature. International Journal of Food Microbiology, 21, 293-303. https://doi.org/10.1016/0168-1605(94)90059-0

[2] Færgeman, N.J., Sigurskjold, B.W., Kragelund, B.B., Andersen, K.V. and Knudsen, J. (1996) Thermodynamics of Ligand Binding to Acylcoenzyme A Binding Protein Studied by Titration Calorimetry. Biochemistry, 35, 14118-14126. https://doi.org/10.1021/bi960545z

[3] Rasmussen, J.T., Faergeman, N.J., Kristiansen, K. and Knudsen, J. (1994) Acyl-CoA Binding Protein (ACBP) Can Mediate Intermembrane Acyl-CoA Transport and Donate Acyl-CoA for Beta-Oxidation and Glycerolipid Synthesis. Biochem J., 299, 165-170.

https://doi.org/10.1042/bj2990165

[4] Rasmussen, J.T., Rosendal, J. and Knudsen, J. (1993) Interaction of Acyl-CoA-Binding Protein (ACBP) on Processes for Which Acyl-CoA Is a Substrate, Product or Inhibitor. Biochem J., 292, 907-913. https://doi.org/10.1042/bj2920907

[5] Cohen Simonsen, A., Bernchou Jensen, U., Faergeman, N.J., Knudsen, J. and Mouritsen, O.G. (2003) Acyl-Coenzyme A Organizes Laterally Inmembranes and Is Recognized Specifically by Acyl-Coenzyme A Binding Protein. FEBS Lett., 552, 253-258. https://doi.org/10.1016/S0014-5793(03)00970-0

[6] Wach, A., Brachat, A. and Pohlmann, R. (1994) New Heterologous Modules for Classical or PCR-Based Gene Disruptions in Saccharomyces Cerevisiae. Yeast, 10, 1793-1808. https://doi.org/10.1002/yea.320101310

[7] Kragelund, B.B., Knudsen, J. and Poulsen, F.M. (1999) Acyl-Coenzyme A Binding Protein (ACBP). Biochimica et Biophysica Acta, 1441, 150-161. https://doi.org/10.1016/S1388-1981(99)00151-1

[8] Kataoka, S. (2005) Functional Effects of Japanese Style Fermented Soy Sauce (Shoyu) and Its Components. J Biosci Bioeng., 100, 227-234. https://doi.org/10.1263/jbb.100.227

[9] Hou, L.H., Song, Q. and Cao, X.H. (2009) Research Progress of Soy-Sauce Flavour. China Brewing, 7, 1-3.

\section{Submit or recommend next manuscript to SCIRP and we will provide best service for you:}

Accepting pre-submission inquiries through Email, Facebook, LinkedIn, Twitter, etc. A wide selection of journals (inclusive of 9 subjects, more than 200 journals)

Providing 24-hour high-quality service

User-friendly online submission system

Fair and swift peer-review system

Efficient typesetting and proofreading procedure

Display of the result of downloads and visits, as well as the number of cited articles

Maximum dissemination of your research work

Submit your manuscript at: http://papersubmission.scirp.org/

Or contact jbm@scirp.org 